\title{
EVOLUÇÃO DA AVICULTURA BRASILEIRA
}

\author{
VOGADO, Gleissa Mayone Silva ${ }^{1}$ \\ VOGADO, Kalene Taty Silva ${ }^{2}$ \\ FONSECA, Wéverton José Lima ${ }^{3}$ \\ FONSECA, Wéverson $\mathrm{Lima}^{4}$ \\ VOGADO, Willamy Fonseca ${ }^{5}$ \\ OLIVEIRA, Augusto Matias de $\mathrm{de}^{2}$ \\ OLIVEIRA, Norberto Matias de $\mathrm{e}^{2}$ \\ LUZ, Carlos Syllas Monteiro ${ }^{3}$
}

\begin{abstract}
RESUMO: Esta revisão teve como objetivo avaliar a evolução da avicultura em vários aspectos, bem como sua produção e tendência ao consumo no Brasil e no mundo. O espaço ocupado pelo Brasil atualmente, foi devido à intensificação no seu processo de produção, relacionado a fatores como introdução de novas tecnologias melhoria genética, uso de instalações mais apropriadas e alimentação racional. As inúmeras inovações na área de genética, nutrição, sanidade e no processo produtivo de forma geral, possibilitaram a produção de frangos com mais peso, em menos tempo e com menor consumo de ração são alguns dos diversos fatores que contribuíram para que o setor alcançasse o patamar atual.
\end{abstract}

Palavras-chave: Consumo. Alimentação racional. Inovações. Processo produtivo.

\section{EVOLUTION OF BRAZILIAN POULTRY}

SUMMARY: This review aims to evaluate the development of the poultry industry in many ways, and their production and consumption trends in Brazil and worldwide. The space occupied by Brazil today, was due to the intensification in the production process related to factors such as introduction of new technologies genetic improvement, use of more appropriate and rational power facilities. The numerous innovations in the field of genetics, nutrition, health and the production process in general, made possible the production of chickens with more weight in less time and with lower feed intake are some of the many factors that contributed to the sector reached the current level.

Keywords: Consumption. Rational power. Innovations. Production process.

\section{INTRODUÇÃO}

O espaço ocupado pelo Brasil atualmente, foi devido à intensificação no seu processo de produção, relacionado a fatores como introdução de novas tecnologias melhoria genética, uso de

\footnotetext{
${ }^{1}$ Graduanda Zootecnia, Universidade Federal do Piauí - (UFPI), Bom Jesus, Brasil. E-mail: gleissa2013@hotmail.com. *Autor para correspondência.

${ }^{2}$ Graduando em Biologia, Universidade Federal do Piauí - (UFPI), Bom Jesus, Brasil.

${ }^{3}$ Programa de Pós-Graduação em Ciência Animal, Universidade Federal do Piauí - (UFPI), Teresina, Brasil.

${ }^{4}$ Programa de Pós-Graduação em Agronomia/Fitotecnia, Universidade Federal do Ceará - (UFC), Fortaleza, Brasil.

${ }^{5}$ Graduando em Pedagogia, Universidade Estudual do Piauí - (UESPI), Bom Jesus, Brazil.
} 
instalações mais apropriadas e alimentação racional. A manutenção desse bom desempenho, num mercado altamente competitivo, exige uma evolução constante, enfocando não apenas os aspectos econômicos e de produtividade, mas também aqueles ligados à qualidade e atendimento das demandas dos consumidores.

De acordo com dados da UBABEF (2013), em 2012, a produção brasileira de carne de frango foi de 12,65 milhões de toneladas, sendo $69 \%$ deste total destinados ao consumo interno e $31 \%$ para exportação, sendo que o volume total de exportação foi de 3,918 milhões de toneladas, para mais de 150 países. E desde a década da 1980, a cadeia produtiva de frango de corte no Brasil apresentou uma significativa transformação, sendo caracterizada por ganhos na produtividade, abertura de novos mercados e também uma maior consolidação da organização e integração entre seus elos (SILVA;SAES, 2005).

O desenvolvimento da avicultura de corte pode ser considerado como a síntese e o símbolo do grande crescimento e modernização do agronegócio brasileiro. Isso porque a atividade avícola reúne em sua estrutura funcional três elementos importantes no cálculo econômico em relação ao capitalismo e em sua configuração atual, que podem ser: tecnologia avançada, eficiência na produção e diversificação no consumo (COELHO;BORGES, 2002).

As inúmeras inovações na área de genética, nutrição, sanidade e no processo produtivo de forma geral, possibilitaram a produção de frangos com mais peso, em menos tempo e com menor consumo de ração são alguns dos diversos fatores que contribuíram para que o setor alcançasse o patamar atual. Destacam-se, nesse caso, as melhorias ocorridas em manejo e ambiência, que aumentaram o bem-estar das aves nos aviários durante a etapa de criação, melhorando assim, seu desenvolvimento.

Esses avanços proporcionaram ganhos de produtividade e eficiência, (ZILLI, 2003) e (GARCIA, 2004). Já de acordo com Tupy e Yamaguchi (1998), eficiência e a produtividade são indicadores de desempenho das unidades produtivas. Por isso, avaliar a eficiência operacional de uma organização pode ajudar a aperfeiçoar seu desempenho atual ou incorporar novas tecnologias a fim de incrementar a competitividade.

Esta revisão teve como objetivo avaliar a evolução da avicultura, bem como sua produção, importância no mercado, seus novos desafios em questões ambientais e tendência ao consumo no Brasil e no mundo.

\section{HISTÓRICO DO FRANGO DE CORTE BRASILEIRO}

A criação de frango de corte para abate, teve na história recente da economia brasileira, um aumento de abates significativo que está intimamente ligado ao avanço tecnológico e 
principalmente a criação na esfera industrial que acabou sendo chamada de avicultura tradicional, favorecendo o patamar atual do Brasil como terceiro maior produtor e primeiro maior exportador do mundo.

O marco inicial da avicultura industrial foi na década de 50, época na qual começou a substituição da antiga avicultura comercial que havia se iniciado nos anos 20 e 30 (SORJ, 1982). Naquela época, deram-se início a muitos estudos sobre a melhor forma de explorar a atividade. Os grandes frigoríficos que detinham a hegemonia no processo extensivo, cederam lugar, sobretudo, aos grupos que conseguiam dominar a nova integração de grãos e carnes brancas (IPARDES, 2002).

O regime de criação intensivo é o mais empregado pelos produtores, nesse sistema, os animais ficam totalmente confinados, e visa um acréscimo na produção e na eficiência da atividade. Esses dados de eficiência podem ser constatados através do trabalho de melhoramento genético das aves, a coleta de dados, a mensuração de variáveis como consumo de alimento a peso corporal, conversão alimentar, mortalidade, rendimento de carcaça, e além disso, o uso de novas tecnologias implantadas em instalação, manejo, nutrição, bem estar e higiene (BOARETTO, 2009).

Ao fazer uma análise do desenvolvimento histórico da atividade, Rizzi (1993), caracteriza a década de 70 como o período mais importante para a evolução da produção de carne de frango. De acordo com Canever et al. (1997), nessa época, a atividade deixou de ser concentrada na região Sudeste e se expandiu para o Sul do país, com Santa Catarina ganhando destaque na produção. Em outras palavras, o setor avícola tem crescido mais do que a economia em geral representando, dessa maneira, um importante papel nas exportações agrícolas do país.

Algumas empresas de Santa Catarina, que produziam suínos e cereais, adotaram a avicultura como forma de diversificação e receberam incentivos pela oferta de crédito e disponibilização de tecnologias importadas, daí o papel de destaque em produtos de qualidade em menos tempo (CANEVER et al, 1997).

\section{PRODUÇÃO DE FRANGOS DE CORTE NO BRASIL}

Desde os anos de 1940, a produção de carne de frango vem se fixando no Brasil, e desde então, tem apresentado um crescimento satisfatório, e a partir desse aumento, nos últimos anos, o país vem ganhando um lugar de destaque no que se refere ao grande cenário mundial. Isso porque, muitos brasileiros mudaram seus hábitos alimentares em relação ao consumo de carne e por outro lado, os consumidores se sustentam no fato de ser a carne de frango, uma proteína animal de maior acessibilidade. 
De acordo com Espíndola (2012), há alguns programas de melhoramento genético que contribuíram para os bons resultados da avicultura brasileira, entre eles se destacam: a Inseminação Artificial (IA); a Transferência de Embriões (TE); a micro manipulação e produção in vitro de embriões; a clonagem e produção de animais transgênicos ou altamente modificados.

Para Rizzi (2004), a formação da indústria brasileira de carne de frango se deu devido à instalação de várias empresas espalhadas por diversas regiões brasileiras. De acordo com França (2000), nos últimos 40 anos, a base técnica do processo produtivo da avicultura de corte tem passado por transformações importantes, tornando-o cada vez mais intensivo no uso de tecnologias.

Frente à retração do mercado interno, em decorrência da recessão generalizada na economia brasileira, a primeira metade dos anos 80 foi o único período de baixo crescimento da produção avícola, mas foi compensado pelo crescimento das exportações. Querendo atender às inúmeras e crescentes exigências dos importadores, as empresas exportadoras brasileiras de frango passaram a investir em melhoria na genética, em tecnologias avançadas e em processos que ajudassem a aumentar a eficiência de toda a cadeia de produção.

Alguns fatores como a utilização de tecnologia avançada, controle sanitário adequado às normas internacionais e taxa de câmbio favorável às exportações, contribuíram para que o Brasil alcançasse resultados significativos e aumentasse a sua vantagem competitiva no mercado exterior, resultando no crescimento de sua produção (IBGE/SIDRA, 2013).

\section{A AVICULTURA E O PEQUENO PRODUTOR}

Buscando formas de diversificação para sua produção, através de cursos formativos ou informações que se referem ao mercado e sua modernização em atividades, o pequeno produtor transforma sua atividade e, assim, contribui para o desenvolvimento do cenário do país. É fator de grande importância financeira para o produtor de pequeno porte, diversificar a produção, já que acaba gerando uma grande oportunidade de vincular sua produção às indústrias, ganhando crédito com o mercado.

O processo que deu início à criação de frangos de corte no Brasil consistia em uma grande quantidade de produtores independentes que estabeleciam relações comerciais com empresas especializadas, que no momento mais recente, foram gradativamente substituídas pelas grandes empresas verticalizadas (FRANÇA, 2006).

A produção integrada na região Sul do Brasil foi caracterizada como sendo uma atividade típica de pequenos produtores, os quais utilizavam mão-de-obra familiar, e cuja decisão de se ligar à agroindústria se justificava tão somente pelas necessidades de sobrevivência, diante de um 
conjunto econômico considerado desfavorável à pequena produção (CLEPS JÚNIOR; PELEGRINI, 2000).

A realidade avícola constitui uma forma diversificada da produção na propriedade rural. Portanto, é necessário que haja preparação dos pequenos produtores para a iniciação e desenvolvimento da atividade, a começar pela construção dos aviários, para que se tenha melhores resultados em suas futuras produções, já que os resultados são positivos no que diz respeito à produção de frango em pequenas propriedades.

\section{IMPORTÂNCIA DA AVICULTURA DE CORTE BRASILEIRA}

As mudanças mais recentes que estão ocorrendo na economia nacional e internacional forçam a modernização das indústrias processadoras e, consequentemente, dos diferentes elos de sua cadeia. Para Canever et al. (1998), esse é o caso da avicultura de corte, na qual a estrutura de produção do frango vivo de corte está se modernizando devido à necessidade de reduzir custos e aumentar a produtividade.

De acordo com Vegro e Rocha (2007), o emprego da tecnologia avançada, constitui-se no elemento central do desenvolvimento do segmento nos últimos anos. Vale salientar que, entre as cadeias produtivas do agronegócio brasileiro, a de carne de frango, configura-se dentre aquelas que mais incorporaram aos novos avanços tecnológicos nas duas últimas décadas. Para Aguiar e Pinho (1998), o uso intenso de mão-de-obra e insumos pelo setor, é constituído como um importante fator de crescimento econômico, com efeitos multiplicadores de renda e emprego em outros setores da economia.

Entre os anos de 1930 e 1996, a capacidade de crescimento dos frangos de corte aumentou 65\% com diminuição de cerca de 50\% na quantidade de ração consumida, reduzindo assim, o tempo de engorda que em 1930 era de 105 dias, para 45 dias, em 1996 (ALVES FILHO; ARAÚJO apud CASIMIRO FILHO; SHIKIDA 1999), o que representa ganhos no em relação ao faturamento industrial.

O agronegócio do frango de corte, tem movimentado volumes elevados de produtos, e a consequência disso está relacionado aos elevados montantes em dinheiro, tanto no mercado interno quanto externo (MAPA, 2009). Considerando que a produção avícola nacional é competitiva e está em ascensão, assim como o consumo interno e externo, é possível que novos mercados sejam prospectados (DELIBERALI et al., 2010) 


\section{TENDÊNCIA AO CONSUMO}

O consumo do frango industrial produziu modificações nos hábitos de consumo popular (FRANÇA; FERNANDES FILHO apud PEREIRA, 2003), pois, como era tradição, as famílias criavam e abatiam os frangos em suas próprias casas. Mas, devido ao sabor e textura bem característicos da carne do frango caipira, ele continua sendo a preferência da população.

Para Ortega (2000), o aumento no consumo de carne de frango, nos últimos anos, é decorrente de vários fatores: por um lado, as estruturas produtivas e de distribuição vêm possibilitando elevadas taxas de conversão de proteína vegetal em animal, a custos cada vez mais baixos. De outro, no que diz respeito à demanda, há diversos fatores, como: mudanças nos hábitos alimentares, motivos religiosos e produto com baixo preço e produzido em larga escala, capaz de atender gigantescos mercados.

Para Voilà e Triches (2013), o aumento no consumo da carne de frango está ligado a quatro fatores básicos: a) substituição das carnes vermelhas, principalmente pela crescente preocupação com a saúde; b) melhor coordenação da cadeia agroindustrial do frango de corte e desenvolvimento de novos produtos e marcas; c) aceitação da carne de frango pela maioria da população; e por fim, d) ganhos de produtividade na agroindústria do frango de corte em relação às melhorias tecnológicas e sanitárias.

O incentivo ao consumo de carne de frango é vantajoso devido este tipo de alimento, pois, é resultante de uma produção bastante intensiva e apresenta melhor resposta em relação ao tempo e à área ocupada, justificando os esforços para aumentar a sua demanda (FERNANDES; PANIAGO; LIMA, 1989).

Para Rizzi (1999), as alterações no consumo e aumento relativo do mercado de carnes de frango, devem-se à ampliação da escala de produção e inovações tecnológicas em sua cadeia produtiva, enquanto que as outras carnes permanecem ainda, com raras exceções, relativamente atrasadas em termos de tecnologia de processo e de matérias-primas.

Com o aumento do consumo de carne de frango no Brasil, este setor do agronegócio aumentou muito sua produção, o que faz com que seja considerado nos dias atuais como um dos setores mais importantes para o agronegócio brasileiro (DESOUZART, 2012). De acordo com Azevedo (2012) “o frango de corte é consumido em 100\% dos domicílios brasileiros”.

\section{NOVOS DESAFIOS PARA A AVICULTURA BRASILEIRA: QUESTÕES AMBIENTAIS}

As forças de mercado imputaram um sistema que, sendo baseado na produção industrial capitalista e, assim, sustentado pela evolução tecnológica, tem contribuído para sérias 
interferências no planeta o que, sem dúvida, está levando a humanidade ao que vários autores denominam de "crise ambiental", consequência da modernidade tão avançada nos últimos tempos. (GIDDENS, 1991; BECK; GIDDENS; SCOTT, 1997; GUIMARÃES apud VIANA et al., 2001; LEFF, 2001; ACSELRAD, 2002).

Vários questionamentos foram levantados e discutidos nos últimos anos pela sociedade quanto às questões ambientais na produção de frango de corte. Estes questionamentos são importantes, pois tal discussão visa possibilitar o desenvolvimento destas cadeias produtivas com sustentabilidade, onde não somente as diretrizes econômicas serão consideradas, mas também as ambientais e sociais (PALHARES, 2004).

Vale ressaltar, que o manejo adequado da cama de aviário poderá colaborar para que os problemas ambientais, decorrentes dos resíduos da avicultura, sejam resolvidos com investimentos em tecnologia. A utilização de biodigestores, dos quais após o processo de fermentação são obtidos o biogás - gás inflamável, e o biofertilizante, pode ser considerada uma das tecnologias utilizadas para aperfeiçoar o balanço energético das propriedades (BELLAVER; PALHARES, 2002)

O processo de biodigestão, tem outra grande importância, devido ao fato de ele não está ligado somente para se obter energia alternativa a partir de resíduos orgânicos, mas na questão do saneamento rural por meio da redução da carga orgânica poluente, além da obtenção de um efluente apropriado para a fertilização do solo (PALHARES, 2004). Ainda, de acordo com o autor, o custo do tratamento dos resíduos deve ser inserido ao custo de produção da atividade, a fim de proporcionar uma maior sustentabilidade à cadeia produtiva.

Os impactos ambientais que estão mais relacionados ao abate de frango industrial é o uso da água e da energia. Levando em consideração o alto nível de concentração de matéria orgânica solúvel ou em suspensão, provenientes do sangue, da gordura, das penas, restos de tecidos, conteúdo das vísceras e da moela das aves, e de desinfetantes; e que o aumento da produção influencia diretamente a quantidade de resíduos gerados no processo de industrialização (MORAES; JUNIOR, 1999).

Em termos ambientais, quando há uma maior concentração na produção de frangos de corte em poucas unidades de produção, ou em uma dada região, faz com que o potencial de poluição que são produzidos nos aviários seja ainda maior. Portanto, não importa se serão produzidos em áreas de maior ou de menor altitude, podendo vir a facilitar o manejo e a redução do maior risco de doenças entre os animais, o que de fato importa, é que não se deve, em hipótese alguma, esquecer de atenuar os riscos ambientais que isso pode causar futuramente. 


\section{CONSIDERAÇÕES FINAIS}

Com o referente estudo, observa-se que um dos principais fatores que fundamentaram a evolução e, consequentemente, o desenvolvimento da avicultura nacional, é a integração dos diversos elos da cadeia de produção, formando, portanto, um complexo agroindustrial altamente interligado que permite o planejamento da atividade e a diminuição dos custos de produção.

Acredita-se que, independentemente dos cenários que possam surgir, a fase é de bastante otimismo e que o mercado brasileiro ainda tem espaço para crescer no setor de carnes, por ser um dos maiores produtores de grãos no mundo e um grande mercado consumidor.

Conclui-se, então, que a avicultura nacional deve adotar como regra, a cautela no planejamento estratégico da atividade avícola, para evitar o aumento excessivo ou a diminuição forçada da produção nacional frente às mudanças no mercado mundial.

\section{REFERÊNCIAS}

ACSELRAD, H.. Justiça ambiental e construção social do risco. Revista Desenvolvimento e Meio Ambiente, UTFPR, n. 5, 49-59 p. jan./jun. 2002.

AGUIAR, D.; PINHO, B.. Agronegócio brasileiro: desafios e perspectivas., Brasília: SOBER Sociedade Brasileira de Economia e Sociologia Rural, 1998.

ALVES FILHO, E.; ARAÚJO, M da P. Origens e desenvolvimento do sistema de produção integrada no Brasil. In: CASIMIRO FILHO, F.; SHIKIDA, P. F. A. (coordenação). Agronegócio e desenvolvimento regional. Cascavel: Edunioeste. 1999.

BECK, U.; GIDDENS, A.; SCOTT, L.. Modernização reflexiva: política, tradição e estética na ordem social moderna. São Paulo: UNESP. 1997.

BOARETTO, T. N. Melhoramento genético em frangos de corte. Revista Formação Informação Zootecnia. v. 1, n.1, maio 2009.

CANEVER, M. D. et al. A cadeia produtiva do frango de corte no Brasil e na Argentina. Concórdia: EMBRAPA-CNPSA. 1997.

CANEVER, M. D. et al. Mudanças tecnológicas na avicultura de corte: implicações sócioeconômicas. Revista de Política Agrícola, São Paulo, v.7, 5-10 p. 1998.

CLEPS JÚNIOR, J. PELEGRINI, F. D. A integração agroindustrial no triângulo mineiro: a Rezende alimentos. Caminhos da geografia, Uberlândia, v.1, n. 1, p. 27-38, 2000. Disponível em: www.ig.ufu.br/volume1.html Acesso em: 30 dez. 2003.

COELHO, C.N.; BORGES, M. O Complexo agroindustrial (CAI) da avicultura. http://www.agricultura.gov.br, Acesso em: 27 nov. 2002. 
DELIBERALI, E. et al. Exportações e habilitações de carne de frango ao mercado internacional: um estudo da mesorregião oeste do Estado do Paraná. Informações Econômicas, v. 40, n. 6, jun. 2010.

DESOUZART, O. Futuro econômico da indústria avícola. AVEWORLD, Ed. 59, ago/set. 2012.

ESPÍNDOLA, C.J. Trajetórias do progresso técnico na cadeia produtiva de carne de frango do Brasil. Revista Geosul, v. 27, n. 53, 89-113 p. jan./jul. 2012.

FERNANDES, S. G.; PANIAGO, E.; LIMA, J. E. de. Análise de alternativas relacionadas com a demanda e a oferta de carnes no Brasil. Revista de Economia e Sociologia Rural, v. 27, n.2, p.437-461 abr./jun. 1989.

FRANÇA, L. R. A reestruturação produtiva da avicultura de corte: Rio Verde (Go) e videira (Sc). 2006. Tese (Doutorado em Zootecnia - Área de Concentração em Produção Animal). Faculdade de Ciências Agrárias e Veterinárias. Universidade Estadual Paulista.

FRANÇA, L. R. de; FERNANDES FILHO, J. F. A evolução da avicultura de corte em Goiás. In: PEREIRA, S. L. O agronegócio nas Terras de Goiás. Uberlândia: EDUFU, 175-211 p. 2003.

GARCIA, L. A. F. Economias de escala na produção de frangos de corte no Brasil. 2004. Tese (Doutorado em Ciências) - Escola Superior de Agricultura Luiz de Queiroz, Universidade de São Paulo.

GIDDENS, A.. As consequências da modernidade. São Paulo: UNESP, 1991.

GUIMARÃES, R.. A ética da sustentabilidade e a formulação de políticas de desenvolvimento. In: VIANA, G. et al. (orgs). O desafio da sustentabilidade: um debate socioambiental no Brasil. São Paulo: Fundação Perseu Abramo, 2001. 43-68 p.

IPARDES- Instituto Paranaense de Desenvolvimento Econômico e Social. Analise da competitividade da cadeia agroindustrial da carne de frango no estado do Paraná. Curitiba. 2002.

LEFF, E.. Saber ambiental: sustentabilidade, racionalidade, complexidade, poder. Petrópolis: Vozes. 2001.

MAPA - Ministério da Agricultura, Pecuária e Abastecimento. Intercâmbio comercial do agronegócio: Principais mercados de destino. Brasília, DF: MAPA/ACS. 2009.

MORAES, L.de M.; JUNIOR, D.R.de P.. Gerenciamento de Resíduos de Abatedouro de Aves: Alternativas de Manejo e Tratamento. In: CONGRESSO BRASILEIRO DE ENGENHARIA SANITÁRIA E AMBIENTAL, 20. Seção III - 019. In: ASSOCIAÇÃO BRASILEIRA DE ENGENHARIA SANITÁRIA E AMBIENTAL; AIDIS, 1999, Rio de Janeiro. Anais... Rio de Janeiro. ABES, 3618- 3627 p. 1999.

ORTEGA, A. C. Competitividade dos complexos agro-industriais de aves suínos do CentroOeste. PROJETO: Programas Setoriais de Promoção da Competitividade do Norte e CentroOeste. Rio de Janeiro: NEDRIJ, IE/UFU, 113 p. 2000.

PALHARES, J.C.P. Água e Avicultura: avicultura industrial. São Paulo. v.8. 14-16 p. 2004. 
PALHARES, J. C. P. Uso da cama de frango na produção de biogás. Circular Técnica. Centro Nacional de Pesquisa de Suínos e Aves, Concórdia, v. 41, p. 01-12, 2004. Disponível em:< www.cnpsa.embrapa.br > Acesso em: 26 nov. 2009.

RIZZI, A. T. Mudanças tecnológicas e reestruturação da indústria agroalimentar: o caso da indústria de frangos no Brasil. 1993. , 203 p. Tese (Doutorado em Economia) -Instituto de Economia, UNICAMP. Campinas.

RIZZI, A. T. Mudanças tecnológicas e reestruturação produtiva na indústria de frangos In: ENCONTRO REGIONAL DE ECONOMIA E ECONOMETRIA DA REGIÃO SUL, 1999, Curitiba. Anais... Curitiba: ANPEC SUL, v. 1, 1-20 p 1999.

RIZZI, A. T. A indústria de frangos no Brasil: constituição e transformações. In: CONGRESSO BRASILEIRO DE HISTÓRIA ECONÔMICA, 3., CONFERÊNCIA INTERNACIONAL DE HISTÓRIA DE EMPRESAS, 4., Anais... 2004, Belo Horizonte, MG,

RODRIGUES, W. O. P et al.. Evolução da avicultura de corte no Brasil. Enciclopédia Biosfera, Centro Científico Conhecer - Goiânia, v.10, n.18; 1668 p. 2014.

IBGE - Instituto Brasileiro de Geografia e Estatística. Sistema IBGE de recuperação automática. SIDRA - Banco de dados pecuária. Disponível em:

http://www.sidra.ibge.gov.br/bda/tabela/protabl.asp?c=1094\&z=t\& =1 \&i=P. Acesso em: 19 maio 2013.

SILVA, C. L.; SAES, M., S. Estruturas e características da cadeia de valor a partir do tipo de governança: uma avaliação preliminar da avicultura de corte paranaense. Informe Gepec, Toledo/ PR, v. 9, n. 1. 2005a.

SORJ, B., POMPERMAYER, M.J., CORADINI, O.L. Camponeses e Agroindústria: Transformação social e representação política na avicultura brasileira. Rio de Janeiro: Zahar, 1982.

TUPY, O.; YAMAGUCHI, L. C. T. Eficiência e produtividade: conceitos e medição. Agricultura em São Paulo, São Paulo, v. 45, n. 2, 39-51 p. 1998.

UBABEF. Relatório anual 2012. Brasília. Disponível em: http://http:// www.ubabef.com.br/. Acesso em 1 ago. 2013.

VEGRO, C.L.R.; ROCHA, M.B. Expectativas Tecnológicas para o Segmento de Carnes de Aves e Suínos. Informações Econômicas, São Paulo, v. 37, n. 5, 15-27 p. 2007.

VOILÀ M.; TRICHES, D. A cadeia de carne de frango: uma análise dos mercados brasileiro e mundial de 2002 a 2010. Instituto de Pesquisas Econômicas e Sociais. Texto n. 44, jan. de 2013.

ZILLI, J. B. Os fatores determinantes para a eficiência econômica dos produtores de frango de corte: uma análise estocástica. 2003. 139 f. Dissertação (Mestrado em Ciências) - Escola Superior de Agricultura Luiz de Queiroz, Universidade de São Paulo, Piracicaba. 